\title{
O desenvolvimentismo
}

\section{cepalino: problemas teóricos e influências no Brasil}

\author{
RENATO PERIM COLISTETE
}

$\mathrm{P}$ ASSADOS MaIs de 50 anos desde a publicação do texto inaugural de Raúl Prebisch na CEPAL (Comissão Econômica para a América Latina), ganha-se cada vez mais o benefício do tempo para avaliar o significado e o impacto das teses elaboradas pelo grupo de economistas e outros cientistas sociais reunidos a partir do final da década de $40 \mathrm{em}$ Santiago do Chile no então recém-criado órgão da ONU. Um dos consensos emergentes após todos esses anos é o de que, mais que um "manifesto" pelo desenvolvimento latino-americano, os autores cepalinos desenvolveram uma estrutura conceitual própria, que deu suporte e legitimidade às propostas de política econômica oriundas da CEPAL. Esse conjunto de proposições teóricas e de políticas econômicas deu substância ao que passou a ser chamado de desenvolvimentismo cepalino, referindo-se o termo às teses dos autores da CEPAL que propunham que a industrialização apoiada pela ação do Estado seria a forma básica de superação do subdesenvolvimento latino-americano.

A teoria do subdesenvolvimento elaborada pela CEPAL alcançou grande sucesso na América Latina. No Brasil em particular, esse sucesso ocorreu não só entre policy makers mas também entre empresários industriais e, ao longo do tempo, no meio acadêmico. A influência cepalina atingiu o auge durante os anos 50 e 60, quando as idéias e os técnicos da CEPAL estiveram no centro dos debates e, muitas vezes, das decisões econômicas no Brasil. Mesmo décadas depois, o papel proeminente exercido pela CEPAL no país ainda impressiona pesquisadores e observadores da história econômica da segunda metade do século XX. Uma primeira questão que continua gerando discussões relaciona-se ao fato da influência da CEPAL ter sido tão significativa: seria simplesmente o resultado do apelo ideológico à industrialização num país ansioso em superar seu passado colonial e subdesenvolvido? Ou o impacto da CEPAL teria sido também resultado da consistência e relevância de seu aparato analítico? Uma outra questão diz respeito à herança intelectual da teoria cepalina: em que medida o pensamento econômico brasileiro assimilou e incorporou métodos de análise e perspectivas da CEPAL?

Apesar de essas questões serem cruciais para uma avaliação da influência da CEPAL no Brasil e na América Latina, elas têm sido relativamente pouco explora- 
das pela literatura significativa. Parte dos numerosos trabalhos sobre a CEPAL publicados nos últimos anos tem se concentrado na exposição da teoria cepalina do subdesenvolvimento, sem o propósito explícito de explorar as possíveis relações entre essa teoria e o sucesso (bem como o posterior declínio) das teses da CEPAL. O objetivo do autor neste artigo é exatamente o de discutir as questões antes indicadas: primeiro, até que ponto o sucesso do desenvolvimentismo cepalino esteve associado à estrutura teórica elaborada pelos autores da CEPAL; segundo, de que forma a teoria cepalina pode ter influenciado o pensamento econômico brasileiro subseqüiente?

O artigo está organizado em duas partes. Em primeiro lugar são discutidos os principais componentes do sistema conceitual e as peculiaridades na formulação da teoria cepalina do subdesenvolvimento que possam ter favorecido a receptividade da CEPAL. Em segundo lugar, procura-se identificar em que aspectos mais gerais a teoria cepalina influenciou as correntes de pensamento econômico no Brasil. Por fim, a última seção resume as principais conclusões obtidas.

\section{A teoria cepalina do subdesenvolvimento: hipóteses e resultados}

A primeira questão a ser tratada consiste em identificar os principais componentes da análise cepalina do desenvolvimento. A importância dessa questão está no fato de que dificilmente a CEPAL teria tido o impacto que teve se as suas propostas de política econômica não estivessem fundamentadas em uma teoria razoavelmente consistente, plausível e relevante para a realidade latino-americana. Assim, pretende-se aqui examinar brevemente as proposições teóricas básicas da CEPAL e procurar identificar quais foram os principais aspectos no plano mais geral da teoria e de sua elaboração que contribuíram para o sucesso do desenvolvimentismo cepalino, não só entre policy makers mas também no pensamento econômico e social da América Latina e do exterior. Em argumento apresentado adiante sustenta-se que não só os aspectos formais da teoria em si (hipóteses, conceitos, resultados), mas também as características de seu processo de formulação e ajuste foram cruciais para o sucesso obtido e, ao mesmo tempo, para os problemas enfrentados pela CEPAL e o desenvolvimentismo cepalino.

O núcleo básico da teoria cepalina do subdesenvolvimento latino-americano e periférico em geral foi formulado entre a chegada de Prebisch em 1949 ao escritório da CEPAL em Santiago, no Chile, e o final dos anos 50. Possivelmente em parte por ter sido elaborada ao longo dos anos, em diversos trabalhos da CEPAL, e em parte por ter surgido no contexto de estudos aplicados sobre as economias latino-americanas, a teoria cepalina manteve-se essencialmente como uma teoria não-formal, na qual a elaboração de hipóteses, conceitos e implicações 
foi conduzida paralelamente à descrição de aspectos da realidade econômica da América Latina. Um dos efeitos dessa última característica foi que a especificação das hipóteses e definições básicas, relações causais entre variáveis e predições da teoria cepalina do subdesenvolvimento foi feita de maneira ambígua nos textos clássicos dos anos 50. Essa é uma característica importante e com significativas conseqüências para a teoria cepalina, como será visto adiante. Ainda assim, é possível identificar o núcleo básico da teoria cepalina do subdesenvolvimento a partir de duas proposições básicas:

- as economias latino-americanas teriam desenvolvido estruturas pouco diversificadas e pouco integradas com um setor primário-exportador dinâmico, mas incapaz de difundir progresso técnico para o resto da economia, de empregar produtivamente o conjunto da mão-de-obra e de permitir o crescimento sustentado dos salários reais. Ao contrário do que pregava a doutrina do livre-comércio, esses efeitos negativos se reproduziriam ao longo do tempo na ausência de uma indústria dinâmica, entendida por Prebisch como a principal responsável pela absorção de mão-de-obra e pela geração e difusão do progresso técnico, pelo menos desde a Revolução Industrial britânica;

- o ritmo de incorporação do progresso técnico e o aumento de produtividade seriam significativamente maiores nas economias industriais (centro) do que nas economias especializadas em produtos primários (periferia), o que levaria por si só a uma diferenciação secular da renda favorável às primeiras. Além disso, os preços de exportação dos produtos primários tenderiam a apresentar uma evolução desfavorável frente à dos bens manufaturados produzidos pelos países industrializados. Como resultado, haveria uma tendência à deterioração dos termos de troca que afetaria negativamente os países latino-americanos através da transferência dos ganhos de produtividade no setor primário-exportador para os países industrializados (1).

Essas duas proposições são altamente ilustrativas da força do argumento cepalino em termos de lógica, abrangência e relevância. Elas geram implicações (reprodução da condição periférica e deterioração dos termos de troca) a partir da articulação de aspectos estruturais domésticos e internacionais reconhecidamente típicos das estruturas econômicas latino-americanas (heterogeneidade econômica, baixa produtividade, salários reduzidos e instabilidade dos preços de bens primários). Apesar disso, a consistência dessas proposições depende de hipóteses adicionais que não foram explicitamente identificadas nos textos cepalinos, sem as quais os resultados antecipados pela teoria não são necessariamente alcançados. Vejamos como isso ocorre. 
A primeira das proposições acima afirma que os efeitos dinâmicos da especialização primário-exportadora sobre o conjunto da economia periférica seriam necessariamente limitados, de modo que somente a industrialização poderia dar origem a um círculo virtuoso de crescimento da produtividade, do emprego e da renda. Essa é uma das implicações centrais da teoria cepalina do subdesenvolvimento - ou seja, a de que a diversificação industrial constituiria o principal meio através do que seria possível a reversão dos efeitos negativos da especialização primário-exportadora na América Latina. Nos textos clássicos da CEPAL, contudo, esse resultado não é definido precisamente em um aspecto importante: em que consistiria a diversificação industrial vista como capaz de reverter o círculo vicioso do atraso periférico? O simples crescimento extensivo da indústria seria suficiente ou seria necessária a diversificação industrial em setores de produção específicos, intensivos em capital e tecnologia, por exemplo?

A resposta a essas perguntas é ambígua se forem tomados os textos dos anos 50 da CEPAL. É possível encontrar passagens em que a expansão industrial traria resultados positivos, primeiro, mediante a absorção do excedente populacional, reduzindo pressões sobre salários e preços do setor exportador; segun-

... a condição periférica seria superada de acordo com o avanço da diversificação industrial ... do, por meio da elevação gradativa da produtividade e renda resultante da introdução de métodos mais eficientes de produção associados às atividades industriais. Nessa perspectiva, a condição periférica seria superada de acordo com o avanço da diversificação industrial e o fim da especialização produtiva - sem maiores qualificações sobre tal processo (2). Por outro lado, é possível também identificar nos textos da CEPAL uma outra interpretação, que aponta os setores industriais que permitiriam internalizar os impactos da difusão da técnica moderna. Para Prebisch, de fato, a expansão das indústrias de bens de capital nos países centrais estaria relacionada a inovações técnicas e reduções de custo, que teriam um efeito positivo sobre a produtividade, os lucros, a demanda de empregos e novos investimentos em máquinas e equipamentos. Sob essa perspectiva, portanto, o núcleo da geração e difusão do progresso técnico seria menos a indústria em geral do que a indústria de bens de capital, tornandose o desenvolvimento dessa última um requisito importante para a superação da condição periférica (3).

Aparentemente, em nenhum momento dos anos 50 a ambigüidade acima mencionada foi resolvida ou mesmo reconhecida de forma explícita. Implicitamente, porém, todo o edifício da teoria cepalina estava fundado na hipótese de que a indústria seria capaz de se tornar o núcleo gerador e difusor de progresso técnico e produtividade. Como isso dificilmente seria alcançado por setores tradi- 
cionais, com baixa intensidade de capital e tecnológica, uma hipótese adicional do argumento cepalino foi a de que a industrialização teria de incorporar setores de bens de produção mais complexos e capazes de gerar e difundir progresso técnico por toda a estrutura industrial. De fato, esta hipótese adicional passou a ser explicitada já no início dos anos 60, quando houve um esforço de qualificação do argumento original cepalino, especificando os requisitos para que a diversificação industrial pudesse ser considerada efetiva (4). Esse ajuste na teoria foi realizado sem referências diretas às teses originais (em quaisquer de suas versões), mas antes argumentou-se que a industrialização observada na América Latina havia demonstrado suas "falhas" e "distorções". Na prática, porém, tal ajuste na teoria cepalina representou o abandono da hipótese mais simples, de que a mera diversificação industrial promoveria o fim da condição periférica.

A segunda proposição da teoria cepalina do subdesenvolvimento apresentada anteriormente - ritmos desiguais de incremento de progresso técnico/produtividade entre centro e periferia e tendência à deterioração dos termos de troca igualmente requer hipóteses adicionais a fim de que os resultados descritos possam ser observados. As hipóteses não-explícitas, embora básicas, do argumento são que, primeiro, a produção primário-exportadora é necessariamente limitada em termos de incorporação de valor agregado e, segundo, que os efeitos de encadeamento das atividades exportadoras sobre outros setores produtivos são restritos.

As hipóteses adicionais acima indicadas são importantes ao excluir avanços técnicos em métodos de produção e qualidade de produto que podem não só contribuir para agregar valor aos bens e para a estabilidade dos mercados de exportação, mas inclusive ter efeitos positivos em termos de difusão tecnológica e de elevação da renda em outros setores produtivos além do setor exportador - inclusive na indústria. Naturalmente, o tipo de produto exportado é relevante para as possibilidades de progresso técnico e incorporação de valor agregado. Embora os textos da CEPAL tenham freqüentemente simplificado a questão ao atribuir características comuns a todos os produtos primários, os tipos de produtos de exportação na América Latina variaram significativamente entre países e regiões, com distintos efeitos potenciais sobre as economias nacionais (5). Independentemente de qualificações como esta, o importante, no entanto, é que a teoria cepalina assumiu como hipótese-chave a impossibilidade de aumento sistemático em valor agregado e de efeitos de encadeamento dinâmicos como características da produção primário-exportadora.

O grande problema com essa generalização é o de que ela não capta casos históricos expressivos em que a produção primário-exportadora esteve associada a inovações técnicas, aumento de valor agregado, difusão tecnológica, efeitos dinâmicos sobre a indústria e elevação no nível de renda da economia como um todo. Esse foi o caso, por exemplo, dos países nórdicos - como Noruega, Dina- 
marca e Finlândia. As experiências dos setores primários nesses países contrastam diretamente com as generalizações da teoria cepalina. Mais importante ainda, as predições da teoria cepalina com relação aos efeitos necessariamente negativos da dependência das economias periféricas quanto à produção primário-exportadora dificilmente coincidem com as trajetórias de desenvolvimento daqueles países, que contaram decisivamente com a exportação de produtos primários e, ao mesmo tempo, experimentaram intensos processos de crescimento dinâmico, inovação tecnológica e expansão sustentada da renda (6).

Quais são as principais conclusões do exposto até agora? Em primeiro lugar, parece possível dizer que alguns dos principais resultados da teoria cepalina do subdesenvolvimento dependem da inclusão de hipóteses adicionais, não-explícitas nos textos cepalinos clássicos dos anos 50. Isso foi visto com relação a duas proposições fundamentais da CEPAL: a do papel central da industrialização para a superação da condição periférica e a da incapacidade da produção primário-exportadora de sustentar um crescimento dinâmico. Em segundo lugar, a imprecisão na formulação das hipóteses centrais na teoria cepalina permitiu que novos resultados, definições e hipóteses fossem incorporados ao longo do tempo, a partir de novos temas que surgiram no horizonte de preocupações dos autores cepalinos.

Essas duas características foram possivelmente decisivas para o sucesso do desenvolvimentismo cepalino entre policy makers e autores da América Latina. A existência de hipóteses não-explícitas permitiu que a teoria cepalina derivasse resultados categóricos sobre as tendências estruturais na periferia, que seriam mais difíceis de se obter caso tais hipóteses tivessem sido explicitamente incluídas. Em outras palavras, o que a teoria cepalina perdeu em precisão e consistência foi possivelmente mais do que compensado pelos ganhos em termos de simplicidade e de apelo entre policy makers e público em geral. Por outro lado, ao mesmo tempo em que incorporaram aspectos históricos reconhecidamente típicos da região, os textos da CEPAL foram suficientemente imprecisos para que novas hipóteses fossem introduzidas sem que fosse alterado o núcleo conceitual básico quanto à caracterização do sistema centro-periferia e do desenvolvimento periférico. Neste sentido, a ambigüidade na especificação dos elementos da teoria foi funcional para que ajustes pudessem ser feitos sem conflitos significativos com o formulado nos textos clássicos.

Ainda assim, em qualquer teoria, a constante qualificação das proposições centrais com novas hipóteses tende a trazer ônus significativos em termos de consistência e capacidade explicativa. É provável que isso tenha ocorrido também com relação à CEPAL, algo que será comentado mais adiante. No momento, porém, a discussão desloca-se para a segunda questão do artigo: em que medida a visão cepalina do processo econômico influenciou o pensamento econômico brasileiro? 


\section{A herança da CEPAL e o pensamento econômico no Brasil}

A influência da CEPAL no Brasil tem sido reconhecida como provavelmente a mais significativa entre os países da América Latina durante o pós-Segunda Guerra Mundial. Embora em graus variados e muitas vezes de maneira difusa, essa influência ocorreu tanto entre intelectuais e policy-markers como entre o empresariado industrial. $\mathrm{O}$ foco desta seção é mais limitado, consistindo na seguinte pergunta: em que medida a concepção da economia desenvolvida pela CEPAL pode ser detectada no pensamento econômico brasileiro? Essa questão por sua vez será tratada aqui brevemente mediante a identificação de características mais gerais da teoria cepalina que passaram a marcar de maneira comum análises e correntes econômicas no Brasil.

A tentativa de identificar influências gerais da teoria cepalina implica que a discussão a seguir não irá examinar em detalhe escolas do pensamento específicas, mas antes procurar isolar traços típicos da abordagem cepalina que permaneceram como herança entre pelo menos parte das abordagens econômicas no país. Duas correntes são selecionadas para análise: a teoria da dependência e a teoria do capitalismo tardio. A teoria da dependência atingiu o auge de seu prestígio nos anos 70 , passando a de-

... a teoria da dependência atingiu o auge de seu prestígio nos anos $70 \ldots$ clinar nas últimas décadas. Já a teoria do capitalismo tardio permanece altamente influente nas análises econômicas no Brasil. O argumento apresentado a seguir é o de que a influência da teoria da CEPAL sobre estas correntes do pensamento econômico brasileiro pode ser detectada em quatro dimensões relacionadas: a ênfase nas estruturas, o papel reduzido dos atores sociais, a predominância de uma perspectiva macro e o desenvolvimento de uma visão peculiar da história.

A ênfase nas estruturas é amplamente reconhecida como uma das características mais marcantes da teoria do subdesenvolvimento da CEPAL. De fato, os escritos de Prebisch são geralmente vistos como os principais representantes da corrente estruturalista nos estudos do desenvolvimento econômico e da economia política internacional (7). Embora marcante na concepção econômica desenvolvida desde os primeiros textos cepalinos, talvez a definição mais precisa da noção de estruturas e seu significado tenha sido proposta nos anos 60, por Osvaldo Sunkel: "dada a estrutura do sistema, fica definida a sua forma de funcionamento, e esta origina os resultados que o sistema produz" (8). Em outras palavras, o funcionamento normal das estruturas econômicas e sociais periféricas gera resultados específicos e pré-determinados: heterogeneidade econômica, baixo 
dinamismo de progresso técnico e produtividade, desigualdade social, deterioração dos termos de troca.

Uma perspectiva similar das estruturas pode ser encontrada em diferentes correntes do pensamento econômico brasileiro. Segundo diversas variantes da teoria da dependência, por exemplo, as estruturas econômicas, sociais e políticas herdadas do período clássico (agro-exportador) da dependência condicionam as trajetórias subseqüentes e podem, no máximo, dar lugar a novas formas de dependência (nova dependência, industrial-periférica, associada-dependente) (9). A rigor, essa concepção do papel das estruturas é idêntica àquela desenvolvida nos textos cepalinos. No mesmo sentido, alguns trabalhos fundadores da chamada Escola de Campinas adotam uma perspectiva similar ao visto acima. $\mathrm{O}$ "capitalismo tardio" e seu modo de funcionamento são determinados por estruturas que caracterizam distintos períodos históricos. Nessa abordagem, as estruturas básicas são as forças produtivas e as relações de produção. Os demais elementos da economia (por exemplo, a ação do Estado, a inserção das empresas estrangeiras e as relações de trabalho) são derivados das características dessas estruturas em momentos específicos da história econômica brasileira - colonial, mercantil-escravista, exportadora-capitalista, industrialização restringida e industrialização pesada (10).

É certo que a CEPAL não foi a única influência estruturalista sobre as teorias da dependência e do capitalismo tardio, uma vez que pelo menos uma herança igualmente significativa foi a de uma tradição marxista com forte ênfase nas estruturas. Mas parece razoável supor que, inclusive pelos próprios vínculos dos principais autores daquelas correntes com a CEPAL, o estruturalismo cepalino deixou uma forte marca sobre o pensamento econômico brasileiro. As perguntas mais importantes aqui, no entanto, são outras: quais são as conseqüências mais relevantes, do ponto de vista analítico, da ênfase nas estruturas? O que é priorizado e deixado de lado nesse tipo de abordagem? A discussão a seguir dedica-se a tratar dessas questões.

A primeira conseqüência que merece ser notada refere-se ao papel dos atores sociais. A despeito das diferenças nos conceitos e teorias, o que unifica as abordagens mencionadas anteriormente é uma concepção em que as estruturas evoluem independentemente das ações dos atores sociais que constituem as sociedades analisadas. Os elementos centrais da análise interagem de tal modo que a sua própria lógica determina certos resultados e exclui outros. Na teoria cepalina, a dominância do setor primário-exportador reproduz baixo progresso técnico, deterioração dos termos de troca e a condição periférica. Na teoria da dependência, as diferentes formas de inserção internacional geram a impossibilidade de um desenvolvimento autônomo e genuíno. Na teoria do capitalismo tardio, as forças produtivas se desenvolvem e dão lugar à plena autodeterminação do capital quando são instaladas as indústrias do setor de bens de produção. Em nenhuma dessas 
abordagens, os atores sociais (como grupos de interesses e classes) e as instituições (como governos e firmas) chegam a cumprir um papel maior que o de realizar as determinações que estão previamente inscritas nas próprias estruturas. Ou seja, os graus de liberdade da ação dos atores sociais são assumidos como altamente reduzidos ou nulos e, conseqüentemente, o foco da análise é dirigido para a lógica de estruturas que estão além do alcance de indivíduos e grupos sociais.

A segunda conseqüência da abordagem estruturalista referese à perspectiva macro da economia. A teoria cepalina desenvolveu-se sobretudo mediante a análise de agregados macroeconômicos, em uma abordagem muito próxima à dos modelos de crescimento keynesianos e neoclássicos que proliferaram a partir dos anos 40. O desenvolvimento econômico foi, de fato, estudado na tradição da CEPAL a partir da interação de agregados como poupança, investimento, progresso técnico e renda nacional. Os trabalhos de Celso Furtado, o principal autor cepalino que procurou incorporar os insights da CEPAL à teoria do desenvolvimento e do crescimento econômico, são particularmente ilustrativos do diálogo entre a perspectiva macro cepalina e as tradições keynesiana e neoclássica (11). Tal perspectiva macro também é comum às teorias da dependência e do capitalismo tardio, embora no caso dessas últimas predominem conceitos de origem marxista ou kaleckiana.

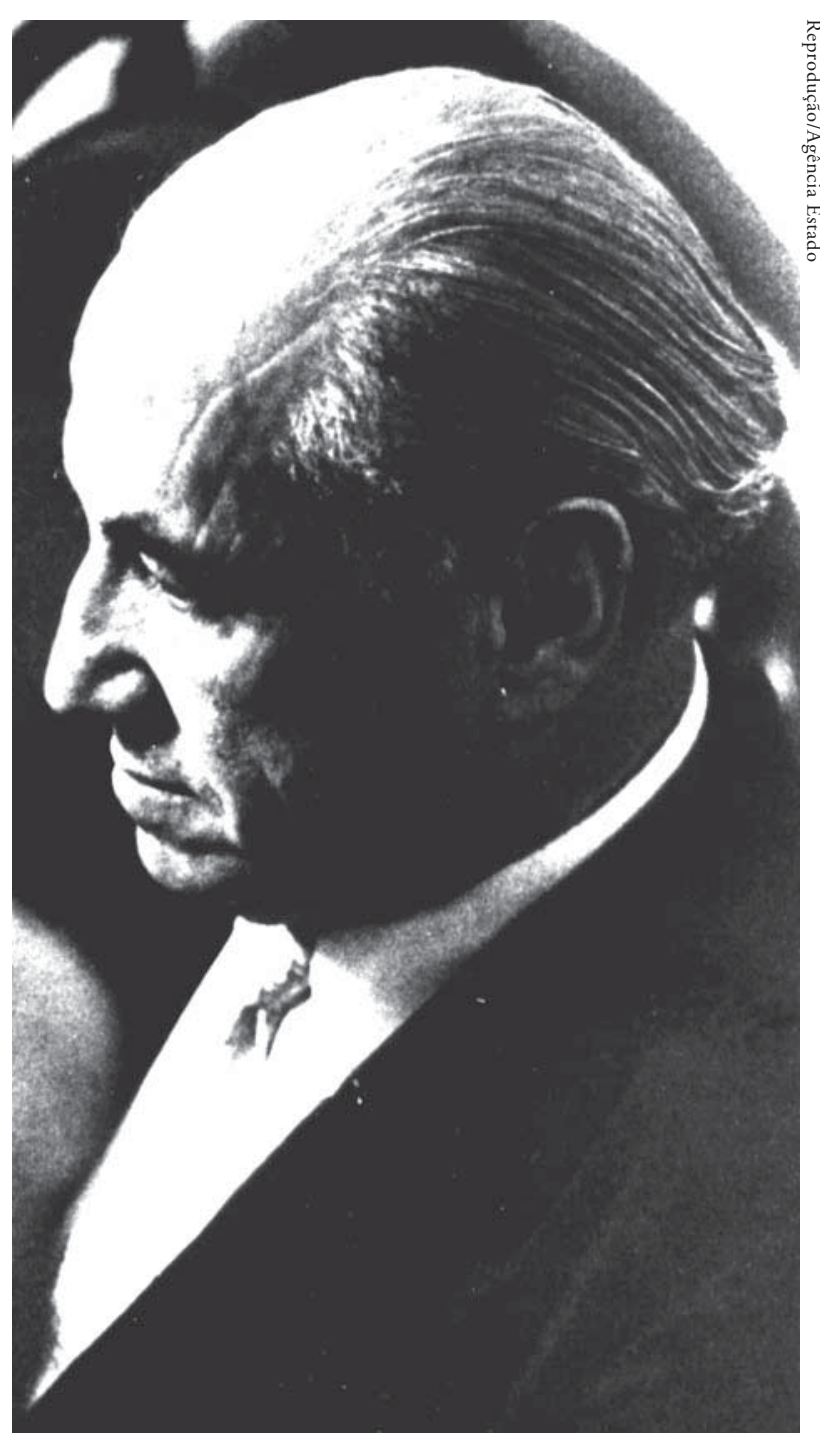

Raúl Prebisch chegon em 1949 ao escritório da CEPAL no Chile

Um resultado importante da perspectiva macro é que unidades econômicas e processos econômicos fundamentais tendem a ser tratados de maneira secundária ou excluídos da análise. Um dos exemplos mais ilustrativos dessa tendência diz respeito às firmas e ao progresso técnico. Uma dimensão pelo menos tão importante de análise quanto o resultado agregado das decisões das firmas e das 
mudanças técnicas (o ressaltado em uma perspectiva macro) é o que ocorre no âmbito das empresas. As decisões estratégicas e as formas institucionais específicas das firmas são geralmente essenciais para o desempenho em termos de crescimento, competitividade e resultados macroeconômicos em geral. Da mesma maneira, a dimensão micro tende a ser crucial para o estudo dos processos de aprendizado, adaptação e busca de alternativas produtivas que constituem parte significativa das mudanças tecnológicas que afetam o desempenho de indústrias e da economia em geral. Em particular, as mudanças incrementais de produtos e processos são um fenômeno que deve ser investigado no plano microeconômico das firmas e indústrias. Neste sentido, uma abordagem que prioriza uma perspectiva dos agregados macro em detrimento do que ocorre na esfera microeconômica tende a eliminar de seu campo de investigação alguns dos processos e unidades mais importantes na análise do desenvolvimento econômico. Essa é, com efeito, uma das características da teoria cepalina, tanto nos seus textos clássicos quanto em trabalhos teóricos mais formalizados como os de Celso Furtado. Da mesma forma, a tecnologia corresponde a uma caixa preta tanto na teoria da dependência quanto na teoria do capitalismo tardio - os processos de aprendizado, adaptação e mudanças incrementais são nesses casos inteiramente excluídos da análise.

Por fim, a terceira conseqüência direta e importante da perspectiva estruturalista diz respeito ao papel ocupado pela história. É freqüentemente atribuído à CEPAL o uso de um método histórico-estruturalista, em que a análise dos processos históricos envolvendo a periferia teria exercido um papel central na teoria cepalina do subdesenvolvimento (12). O mesmo é reivindicado tanto pela teoria da dependência como, de maneira ainda mais enfática, pela teoria do capitalismo tardio. O lugar ocupado pela história nessas teorias, porém, é peculiar no sentido de que, em todas elas, a análise histórica se concentra essencialmente em uma caracterização das estruturas consideradas mais importantes.

A caracterização histórica das estruturas é particularmente relevante para estudos comparativos e periodizações, sobretudo na teoria cepalina e na teoria da dependência. Esse tipo de análise histórica, contudo, tende a ser muito menos direcionado para outros elementos da economia - tais como atores sociais, firmas, idéias e instituições. Em grande medida, essa orientação decorre do próprio papel secundário ocupado por tais elementos nas abordagens estruturalistas, como foi comentado antes. Um dos efeitos disso é que onde grupos sociais, firmas, idéias e instituições podem ter um papel relevante em processos de mudança econômica e condicionamento de diferentes trajetórias históricas, a análise estruturalista mostra-se particularmente pouco equipada.

A dificuldade de incorporar a história na perspectiva estruturalista ainda aparece freqüentemente em situações nas quais descrições históricas se limitam a ilustrar tipologias ou análises comparativas, sem que de fato contribuam decidi- 
damente para o argumento ou sejam efetivamente incorporadas nele. Aparentemente, este é o caso da teoria da dependência e seu uso prático do chamado método histórico-estrutural (13). O mesmo poderia ser dito acerca da teoria do capitalismo tardio, em que a ação do Estado, o comportamento de empresários e as formas assumidas pelas relações de trabalho, por exemplo, já são previamente definidos pelas estruturas em períodos históricos específicos (14).

\section{Conclusões}

Sob a liderança intelectual de Raúl Prebisch, os autores ligados à CEPAL foram capazes de articular uma abordagem original sobre as economias latinoamericanas, que constituiu uma teoria do subdesenvolvimento periférico que teve significativo impacto sobre as idéias e as políticas econômicas na América Latina. O desenvolvimentismo cepalino encontrou um terreno particularmente fértil no Brasil, onde as suas teses tiveram alguns de seus mais criativos divulgadores (como Celso Furtado) e um ambiente altamente receptivo entre técnicos governamentais e empresários industriais. A primeira conclusão a que se chegou no presente artigo é a de que a influência da CEPAL no Brasil foi não só favorecida pela atração que as idéias desenvolvimentistas exerceram entre elites econômicas interessadas em uma política industrializante, mas também dependeu das características internas da teoria cepalina.

De fato, a teoria do subdesenvolvimento da CEPAL foi altamente eficiente tanto em termos de argumentação lógica como porque se apoiava em características amplamente reconhecidas como típicas da realidade latino-americana. A teoria cepalina também beneficiou-se da maneira peculiar com que foi elaborada ao longo dos anos. O seu núcleo conceitual básico foi formulado de maneira relativamente imprecisa, de forma que hipóteses não-explícitas podiam ser tão importantes como as explicitamente introduzidas no argumento. Ao mesmo tempo, o próprio núcleo teórico básico sofreu qualificações substantivas com o passar dos anos. Antes de constituírem uma desvantagem, como seria possível concluir a partir de uma perspectiva da ciência estritamente refutacionista, os ajustes permitiram que a teoria cepalina incorporasse novos temas e questões que passaram a ser motivo de atenção da CEPAL. Deste modo, a discussão acima sugere que a ambigüidade e a flexibilidade da teoria cepalina foram decisivas para consolidar sua influência pelo menos nos anos 50 e 60 .

Ainda assim, a constante qualificação das proposições centrais com novas hipóteses acabou minando a consistência da teoria cepalina. As primeiras alterações na teoria da CEPAL ocorreram já no início dos anos 60, quando foi feito um esforço de especificação mais precisa dos requisitos para que a diversificação industrial pudesse ser considerada efetiva - isto é, capaz de superar a condição periférica. Outras mudanças teriam lugar nos anos subseqüentes, muito mais radicais, 
e que levariam a proposições mais deterministas sobre os limites e problemas do desenvolvimento latino-americano e periférico - particularmente através do conceito de dependência, que passou a ser elaborado por autores cepalinos como Celso Furtado e Osvaldo Sunkel. Parece razoável dizer, portanto, que essas alterações substanciais reduziram a consistência interna e a capacidade explicativa da teoria cepalina, contribuindo para o declínio relativo de sua influência frente a outras correntes teóricas já a partir da segunda metade dos anos 60 .

Apesar desse declínio relativo, a CEPAL deixou marcas profundas no pensamento econômico brasileiro. $\mathrm{O}$ argumento desenvolvido no artigo sustenta que, especialmente a ênfase nas estruturas, típica da teoria cepalina, continuou a orientar parte importante das análises econômicas no Brasil. Com isso, algumas conseqüências diretas da perspectiva estruturalista da CEPAL também foram herdadas por correntes teóricas posteriores: o reduzido papel de atores sociais, a perspectiva macro que tende a excluir unidades e processos importantes na esfera microeconômica e, por fim, uma análise histórica basicamente formal.

Resumidamente, portanto, a discussão aqui realizada chegou a resultados bem específicos quanto às questões formuladas no início: as características formais e a flexibilidade da teoria foram realmente importantes para o sucesso do desenvolvimentismo cepalino e a sua herança intelectual pode ser nitidamente detectada em correntes influentes do pensamento econômico brasileiro. Se essas conclusões forem verdadeiras, o estudo da teoria cepalina continua sendo importante, em primeiro lugar, para se compreender melhor as referências intelectuais que têm condicionado estratégias econômicas no Brasil desde os anos 50.

Em segundo lugar, o estudo das teorias da CEPAL também é importante porque a herança estruturalista do desenvolvimentismo cepalino permanece sendo marcante na forma pela qual correntes teóricas atuais interpretam a economia e identificam temas e aspectos da realidade econômica que são privilegiados ou deixados de lado em suas análises. A possibilidade, portanto, de revisão de aspectos insatisfatórios dos resultados obtidos pela CEPAL e correntes teóricas por ela influenciadas, assim como a abertura de novos campos de pesquisa em Economia e História Econômica que foram negligenciados pela perspectiva estruturalista, parecem depender ainda estreitamente da continuidade da pesquisa sobre as distintas dimensões da influência do desenvolvimentismo cepalino no Brasil.

\section{Notas}

1 Sobre esses pontos ver Octávio Rodriguez. Teoria do subdesenvolvimento da Cepal. Rio de Janeiro, Forense, 1981 e Adolfo Gurrieri. La economia política de Raúl Prebisch, in: Adolfo Gurrieri (org.). La obra de Prebisch en la Cepal. México, Fondo de Cultura Económica, 1982, v. 1. 
2 Ver, por exemplo, Raúl Prebisch. O desenvolvimento econômico da América Latina e alguns de seus problemas principais(1949), in: Ricardo Bielschowsky (org.). Cinqüenta anos de pensamento na Cepal. Rio de Janeiro, Record, 2000, v. 1, p. 78.

3 Raúl Prebisch. Estudo Econômico da América Latina - 1949; e Problemas teóricos e práticos do crescimento econômico (1952), in: Bielschowsky (org.). Cinqüenta anos, v. 1, p. 166-167 e 204, respectivamente.

4 Gurrieri. La economia política de Raúl Prebisch, p. 60-62.

5 Rosemary Thorp. Progress, poverty and exclusion. An economic history of Latin America in the 20th century. Washington, IDB, 1998, p. 87-95.

6 Ver D. Senghaas. The European experience. A historical critique of development theory. Lemington Spa, Bergen, 1985.

7 Robert Gilpin. The political economy of international relations. Princeton, Princeton University Press, 1987, p. 274-81.

8 Osvaldo Sunkel. Desenvolvimento, subdesenvolvimento, dependência, marginalização e desigualdades espaciais: por um enfoque totalizante, in: Bielschowsky (org.), Cinqüenta anos, v. 2, p. 526.

9 Para uma síntese, ver Peter Evans. A tríplice aliança. As multinacionais, as estatais e o capital nacional no desenvolvimento dependente brasileiro. $2^{2}$. ed., Rio de Janeiro, Zahar, 1982, p. 37-44.

10 João Manuel C. de Mello. O capitalismo tardio. $3^{\text {a }}$. ed., São Paulo, Brasiliense, 1984.

11 Celso Furtado. Teoria e política do desenvolvimento econômico (1967). São Paulo, Abril Cultural, 1983.

12 Ricardo Bielschowsky. Cinqüenta anos de pensamento na Cepal - uma resenha, in: Bielschowsky (org.). Cinqüienta anos, v. 1, p. 21-22.

13 Robert Packenham. The dependency movement. Scholarship and politics in development studies. Cambridge, Mass., Harvard University Press, 1992, p. 66-72.

14 Mello. Capitalismo tardio, p. 114-115.

RESUMO - PASSADOS mais de 50 anos de sua criação, a CEPAL continua sendo uma fonte de influências e um importante tema de pesquisa sobre a história econômica brasileira e latino-americana como um todo. Apesar do contínuo interesse que a teoria cepalina continua gerando atualmente, os estudos sobre a CEPAL têm se dedicado relativamente pouco ao exame dos motivos da grande influência alcançada pela teoria cepalina do subdesenvolvimento, nos anos 50 e 60 principalmente, entre policy makers, empresários e autores em geral. Igualmente, a literatura raramente tem procurado estimar o impacto da CEPAL sobre o pensamento econômico na América Latina e no Brasil, em particular. O presente artigo tem por objetivo adiantar hipóteses de interpretação sobre essas duas 
questões, ou seja, os determinantes da influência cepalina nos anos 50 e 60 e seu impacto entre as correntes econômicas subseqüentes. $\mathrm{O}$ argumento apresentado no artigo sugere que parte importante da influência cepalina nos anos 50 e 60 deveu-se à sua estrutura teórica e conceitual - consistente e relevante, mas ao mesmo tempo essencialmente imprecisa e ambígua. O artigo também sustenta que a teoria cepalina foi e continua sendo influente entre correntes econômicas no Brasil. O artigo concentra-se em duas tradições teóricas, a teoria da dependência e a do capitalismo tardio, e argumenta que ambas incorporam características centrais da abordagem cepalina - a ênfase nas estruturas, o papel reduzido dos atores sociais, a predominância de uma perspectiva macro e o desenvolvimento de uma visão formal da história.

ABSTRACT - MORE than fifty years since its foundation, the Economic Commission for Latin America (ECLA) continues to be a source of influence and an important research topic on the Brazilian and Latin-American economic history. Despite the enduring appeal of the cepalina theory, the scholarly studies on ECLA have done little to examine the reasons why the ECLA's underdevelopment theory was so prominent among policy makers, entrepreneurs and scholars, particularly during the 1950s and 1960s. Likewise, the historiography has rarely attempted to assess ECLA's impact over other economic approaches in Latin America and Brazil in particular. This article aims to advance hypotheses about both issues, that is, the determinants of the cepalina influence during the 1950s and 1960s, and its impact on later economic approaches. The view presented in the article is that the influence exerted by ECLA is a great deal explained by the features of its theoretical and conceptual framework - it was consistent and relevant, on the one hand, and ambiguous and vague, on the other. The article also argues that the cepalina theory was and continues to be influential among economic approaches in Brazil. The article addresses two approaches, the dependency theory and the late capitalism theory, and maintains that both took over some central features which marked the ECLA theory - the emphasis on structures, the minor role of social actors, the stress on a macro perspective and the development of a formal view of history.

Renato Perim Colistete é professor do Departamento de Economia da Universidade Estadual Paulista (Unesp), campus de Araraquara.

O autor agradece a ajuda de Renata Cipolli D'Arbo, que generosamente compartilhou resultados ainda inéditos da pesquisa para a sua dissertação na Pós-Graduação em Economia, Área de Concentração História Econômica, da Unesp. Deseja também agradecer a leitura e os comentários cuidadosos de Cláudia Heller, Maria Beatriz Lessa Guimarães, Maria Lúcia Lamounier e Maurício Coutinho. 